\title{
Healing racism in Canadian health care
}

\author{
Yvonne Boyer JD LLD
}

Cite as: CMAJ 2017 November 20;189:E1408-9. doi: 10.1503/cmaj.171234

$\mathbf{R}$ acism in the Canadian health care system is endemic. Recent reports ${ }^{1,2}$ have highlighted its preponderance in central Canada, where Indigenous women have been coerced into sterilization and Indigenous men have been ignored in emergency departments, left to suffer and, in at least one tragic case, to die. Canada's current model of delivering health care fails either to show an understanding of or to address the subset of health determinants that affect Indigenous patients. Ingrained problems of racism and discrimination will not be solved until the system is changed so that health care is delivered in a way that is culturally competent and inclusive of an Indigenous model.

In July 2017, the Saskatoon Health Region commissioned an external review in response to media reports of Aboriginal women being coerced into tubal ligation immediately after childbirth in a Saskatoon Health Region hospital; the review found several structural problems. ${ }^{1}$

Sixteen Aboriginal women contacted the reviewers and seven interviews were completed. All of the women felt coerced into having a tubal ligation postdelivery in the Saskatoon Health Region, most believing it to be reversible as a type of birth control. The women shared that nurses, social workers and physicians pressured them while they were at their most vulnerable, either in the throes of labour or immediately postdelivery. They stated they felt powerless to resist the coercion and have suffered immensely as a result of having tubal ligation.

The report concluded that the Saskatoon Health Region promotes racist and discriminatory health care for Indigenous women. It suggested structural change that is inclusive of culturally relevant health care, and that health professionals be educated and made sensitive to Indigenous history and the unique health care requirements of the people they serve.

An interim report released in September 2017 after a multidisciplinary inquest into the death of Brian Sinclair ${ }^{2}-$ a 45-year-old First Nations man who died of a treatable bladder infection in 2008, after being ignored for 34 hours in the emergency department of the Health Sciences Hospital in Winnipeg - detailed systemic failures at many levels.

When evaluating the circumstances of his death, the working group identified a sequence of racist events that had occurred. For instance, Sinclair was visible to the emergency department staff, who ignored him because they assumed he was homeless

\section{KEY POINTS}

- Indigenous peoples face systemic racism and discrimination in the Canadian health care system, as identified by two recent reports.

- The health care system is set up to ignore the colonial history facing Indigenous patients.

- Structural changes to the current system are urgently needed to address these failures.

or intoxicated or just hanging around. The staff did not question why he remained in the waiting room at any point during the 34-hour interval after he wheeled himself in. Even when he began vomiting and slumping further in his wheelchair, the staff did not consider him to be in distress. When the public intervened, the staff quickly quelled their concern by insisting that Sinclair was either sleeping or intoxicated and not sick at all. The working group report suggested that an antiracist policy be implemented immediately, with a monitoring mechanism to evaluate its ongoing effectiveness.

Systemic racism in health care is not unique to Canada. It is also pervasive in other countries, as outlined in a recent report from the College of Family Physicians of Canada. ${ }^{3}$ In New Zealand and Australia, for example, Indigenous peoples are unlikely to get timely access to coronary angiography or revascularization following acute myocardial infarction in spite of high rates of cardiovascular disease. Maori patients reported health care issues similar to those of Indigenous people in Canada, including gaps in understanding of the patient experience and beliefs that the patients are responsible for their own poor health status. The report noted, however, that when providers of health care for the Maori were made aware of these findings, they were motivated to change their behaviour and made efforts to increase their understanding of Maori culture. These are but a few of the examples of "interpersonal or relational racism" that can lead to suboptimal medical treatment, but that may also be addressed through effective interventions.

In Canada, Indigenous peoples carry the intergenerational trauma of the residential school system, and its myriad tentacles of physical and sexual abuse. Such policies were rooted in racism 
and colonial perspectives of superiority and wardship beliefs. ${ }^{4}$ Today, a substantial power imbalance still exists between nonIndigenous health care providers and Indigenous peoples, which underpins many of their unacceptable experiences in the health care system. ${ }^{5}$ Yet this problem is not well understood, or even perceived, by many health professionals. Most do not consider the substantial historical and social drivers of illness and presentation of illness in Indigenous patients. ${ }^{5}$ Furthermore, interventional medical research has largely failed to consider the unique aspects of involving Indigenous patients in research. The design of most research studies aligns with the colonial framework that maintains health inequality. ${ }^{6}$

The reports from Saskatchewan and Manitoba both stated that structural changes to health care must include input from Indigenous advisory committees consisting of elders and grandmothers who are given an equal voice. ${ }^{1,2}$ Without participation from the people who are affected, any planned changes to the way health care is structured and delivered will be ineffectual. Educating health care professionals in cultural competency is also critical to improving health care for Indigenous peoples. ${ }^{5}$

Facilitating deep structural change will require the creation of new policies to address racism and discrimination - policies that commit resources for independent investigations when complaints are filed by or on behalf of Indigenous patients.

We have missed many opportunities to advance the health and well-being of Indigenous peoples in Canada, and Indigenous peoples are paying the price for these repeated failures. The appointment of the previous minister of health to a new position of Minister for Indigenous Services marks an opportunity for Canada to take a comprehensive approach to dismantling endemic racism in public services, and addressing the associated failures. It is time to develop and establish policies that reflect the humanity of Indigenous peoples and support the health profession's duty of care to Indigenous peoples in Canada.

\section{References}

1. Boyer Y, Bartlett J. Tubal ligation in the Saskatoon Health Region: the lived experience of Aboriginal women [external review]. Saskatoon Health Region; 2017 July 27. Available: https://www.saskatoonhealthregion.ca/DocumentsInternal/Tubal_ Ligation_intheSaskatoonHealthRegion_the_Lived_Experience_of_Aboriginal_ Women_BoyerandBartlett_July_22_2017.pdf (accessed 2017 Oct. 30).

2. Out of sight: a summary of the events leading up to Brian Sinclair's death and the inquest that examined it and the interim recommendations of the Brian Sinclair Working Group [report]. The Brian Sinclair Working Group; 2017. Available: http:// libguides.lib.umanitoba.ca/ld.php?content_id=33973085 (accessed 2017 Oct. 30).

3. Indigenous Health Working Group. Health and health care implications of systemic racism on Indigenous peoples in Canada [fact sheet]. Mississauga (ON): College of Family Physicians of Canada; 2016. Available: www.cfpc.ca/uploadedFiles/ Resources/_PDFs/SystemicRacism_ENG.pdf (accessed 2017 Oct. 30).

4. Boyer Y. Moving Aboriginal health forward: discarding Canada's Legal barriers. Vancouver: Purich Publishing, Ltd.; 2014:72-90, 137.

5. Allan B, Smylie J. First peoples, second class treatment: the role of racism in the health and well-being of Indigenous peoples in Canada. Toronto: Wellesley Institute; 2015.

6. Jull J, Whitehead M, Petticrew M, et al. When is a randomised controlled trial health equity relevant? Development and validation of a conceptual framework. BMJ Open 2017;7:e015815.

\section{Competing interests: None declared.}

This article was solicited and has not been peer reviewed.

Affiliation: University of Ottawa Centre for Health Law, Policy and Ethics, Ottawa, Ont.

Correspondence to: Yvonne Boyer, yboyer@uottawa.ca 